\title{
On A New Arithmetic Function
}

\author{
P. Das ${ }^{1}$ and K.C. Chowdhury ${ }^{2}$ \\ 1. Department of Mathematics, Cotton Colleges state University, Gwahati, 71001, India \\ 2. Department of Mathematics, Gauhati University, Guwahati-781014, India
}

Received: January 16, 2017 / Accepted: February 15, 2017 / Published: April 25, 2017.

\begin{abstract}
Here we explore some fundamental aspects of what may be termed as a new arithmetic function (defined notionally as the $\mathrm{T}$ function) together with its possible inverse $\left(\mathrm{T}^{-1}\right)$, as it is not in frequent discussion among the number theorists.
\end{abstract}

Key words: Arithmetic function, Pascal triangle, digital multiplicative, additive, k-additive, encryption, decryption

\section{Introduction}

Arithmetic functions appear and are employed in studies on the properties of numbers. However, the theory of arithmetic functions is also of independent interest. The laws governing the variations of arithmetic functions cannot usually be described by simple formulas, and the asymptotic behaviour in terms of numerical functions is determined. Since many arithmetic functions are not monotone, the study of their average values is of great importance. An important class of arithmetic functions is constituted by the multiplicative arithmetic functions and the additive arithmetic functions. The most commonly occurring arithmetic functions have traditional symbolic notations [3]: $\phi(n)$ is the Euler function; $d(n)$ or $\tau(n)$ is the number of divisors; $\mu(\mathrm{n})$ is the Möbius function; $\Lambda(\mathrm{n})$ is the Mangoldt function; $\sigma(\mathrm{n})$ is the sum of divisors of the number $n$. Arithmetic functions also include the integral part of a number, $[x]$, and the fractional part of a number, $\{x\}$.

We now introduce our new arithmetic function T(n) and highlight some routine-type characteristics of the said function. $\mathrm{T}$ is defined for any natural $\mathrm{n}$ with

Corresponding author: K.C. Chowdhury, Department of Mathematics, Gauhati University, Guwahati-781014, India. Research field: Algebra, Number theory, Topology, Graph theory. E-mail: chowdhurykc@yahoo.com. respect to its decimal representation that appears as the product of the successor integers appearing in the corresponding presentation. In this context we mention another paper by R. Kumarmuthamulai [2] related to a new arithmetic function.

In this fundamental paper we'll present some restricted formulations of the function with some theoretical vigour and discuss the aspects specifically so as to cover some sort of elaboration such as for what values of the number $n, T(n)=n, T(n)=n+1, T(n)=n-1$, $\mathrm{T}(\mathrm{n})=\mathrm{n}-20, \quad \mathrm{~T}(\mathrm{n})=\mathrm{n}-2, \quad \mathrm{~T}(\mathrm{n})=7 \mathrm{n} / 8, \quad$ and $\quad$ in general $\mathrm{T}(\mathrm{n})=\mathrm{kn}$, with $\mathrm{k} \in \mathrm{Q}^{+}$. Also we attempt to answer some finite series sum of such functional values like $\mathrm{T}(0)+\mathrm{T}(1)+. .+\mathrm{T}\left(10^{\mathrm{k}}-1\right)$ leading to a hint for more generalization of the type.

We also discuss about the possible domain of the inverse of such a function with the help of the convolution operation etc.

Moreover we justifiably see the existence of another new notion, the so called prime-base number systems. Here the domain would be the set integers in different prime- number bases and co-domain is that of usual decimal presentation, such a function would give some interesting computer biased information in respect of such presentations. Finally we analyze the possibility of digital generalized additive property of such a function together with its possible maximum limit. 


\section{Preiliminaries}

Let the positive integer $N=a_{n} a_{n-1} a_{n-2} \ldots a_{2} a_{1} a_{0}$, where $a_{i}$ are digits like $0,1, \ldots, 9$.

Thus $N=\mathrm{a}_{\mathrm{n}} 10^{\mathrm{n}}+\mathrm{a}_{\mathrm{n}-1} 10^{\mathrm{n}-1}+\ldots .+\mathrm{a}_{2} 10^{2}+\mathrm{a}_{1} 10+\mathrm{a}_{0}$ where $0 \leq \mathrm{a}_{\mathrm{i}} \leq 9$ and $\mathrm{a}_{\mathrm{n}} \neq 0$.

We agree to write such a number in the form $\underline{a_{n} a_{n-1} a_{n-2} \ldots a_{2} a_{1} a_{0}}$ to make it distinct from $\left.a_{n} \times a_{n-1} \times a_{n-2} \times \ldots a_{2} \times a_{1} \times a_{0}\right)$. Here $a_{n} a_{n-1} a_{n-2} \ldots a_{2} a_{1} a_{0}=a_{n} \cdot a_{n-1} \cdot a_{n-2} \ldots a_{2} \cdot a_{1} \cdot a_{0}=$ $a_{n} \times a_{n-1} \times a_{n-2} \times \ldots a_{2} \times a_{1} \times a_{0}$, the product of $a_{n}, a_{n-1}, a_{n-2} \ldots a_{2}, a_{1}, a_{0}$

\subsection{Definition}

We define the function $T: N \rightarrow N$ so that, $\mathrm{T}(\mathrm{N})=\left(\mathrm{a}_{\mathrm{n}}+1\right)\left(\mathrm{a}_{\mathrm{n}-1}+1\right) \ldots . .\left(\mathrm{a}_{2}+1\right)\left(\mathrm{a}_{1}+1\right)\left(\mathrm{a}_{0}+1\right)$

Thus, $\underline{123}=1.10^{2}+2.10+3$ and is our ordinary number 123 in decimal presentation.

Now without going to the theory of the function, we work out some examples for clear understanding of the same

$\mathrm{T}(3079)=4 \cdot 1 \cdot 8 \cdot 10=320=4 \cdot 8 \cdot 10=\mathrm{T}(379)=2 \cdot 2 \cdot 2 \cdot 4 \cdot 2 \cdot 5=$ $\mathrm{T}(111314)$

thus the function $\mathrm{T}$ is not onto. And to get an inverse of such a $\mathrm{T}$ we proceed as follows:

\subsection{Definition}

We define; $T^{l}(X)=$ the smallest $\mathrm{N}$ for which $\mathrm{T}(\mathrm{N})$ $=\mathrm{X}$.

Then we search for viz., $\mathrm{T}^{-1}(54)$ and $\mathrm{T}^{-1}(720)$, say. For the purpose, searching for a two digit solution, we get two factors of 54 where one factor is as small as possible (of course, no factor may be greater than 10). This leads to 6, 9; hence the answer is 58. Next we search for three factors of 720 , each number not greater than 10 , with one as small as possible. Clearly this factor must be greater than 7 , so we use $8,9,10$. This leads to the answer 789 . $\mathrm{T}(789)=8 \times 9 \times 10=720$.

\subsection{Definition}

An arithmetic function $\mathrm{f}$ satisfies digital multiplicative property for $n \in N$, if

$$
\mathrm{n}=a_{n} a_{n-1} a_{n-2} \ldots a_{2} a_{1} a_{0},
$$

$$
\mathrm{f}\left(\underline{a_{n} a_{n-1} a_{n-2} \ldots a_{2} a_{1} a_{0}}\right)=\mathrm{f}\left(\mathrm{a}_{\mathrm{n}}\right) \mathrm{f}\left(\mathrm{a}_{\mathrm{n}-1}\right) \ldots \mathrm{f}\left(\mathrm{a}_{0}\right) .
$$

\subsection{Definition}

An arithmetic function $\mathrm{f}$ satisfies digital additive property if for $n \in N$, if

$$
n=\underline{a_{n} a_{n-1} a_{n-2} \ldots a_{2} a_{1} a_{0}},
$$

$\mathrm{f}\left(\underline{a_{n} a_{n-1} a_{n-2} \ldots a_{2} a_{1} a_{0}}\right)=\mathrm{f}\left(\mathrm{a}_{\mathrm{n}}\right)+\mathrm{f}\left(\mathrm{a}_{\mathrm{n}-1}\right)+\ldots+\mathrm{f}\left(\mathrm{a}_{0}\right)$.

\subsection{Definition}

An arithmetic function $\mathrm{f}$ satisfies digital $\mathrm{k}$-additive property if for $k, n \in N$, if $\mathrm{n}=\underline{a_{n} a_{n-1} a_{n-2} \ldots a_{2} a_{1} a_{0}}$, $\mathrm{f}\left(\underline{a_{n} a_{n-1} a_{n-2} \ldots a_{2} a_{1} a_{0}}\right)=\mathrm{k}\left[\mathrm{f}\left(\mathrm{a}_{\mathrm{n}}\right)+\mathrm{f}\left(\mathrm{a}_{\mathrm{n}-1}\right)+\ldots+\mathrm{f}\left(\mathrm{a}_{0}\right)\right]$.

Note: If for $n \in N$, $\mathrm{f}$ is digital 1-additive, then for $n$ it is digital additive.

\subsection{Cryptographic Aspects}

Cryptography is the study of methods of sending messages in disguised form so that only the intended recipients can remove the disguise and read the message [1]. The message we want to send is called the plaintext and the disguised message is called the ciphertext.

An enciphering transformation is a function that takes any plaintext message unit and gives us a ciphertext message unit. In other words, it is a map $f$ from the set $\mathrm{P}$ of all possible plaintext message units to the set $\mathrm{C}$ of all possible ciphertext message units. We shall always assume that $f$ is a 1-to- 1 correspondence. That is, given a ciphertext message unit, there is one and only one plaintext message unit for which it is the encryption. The deciphering transformation is the map $\mathrm{f}^{-1}$ which goes back and recovers the plaintext from the ciphertext. We can represent the situation schematically by the diagram 


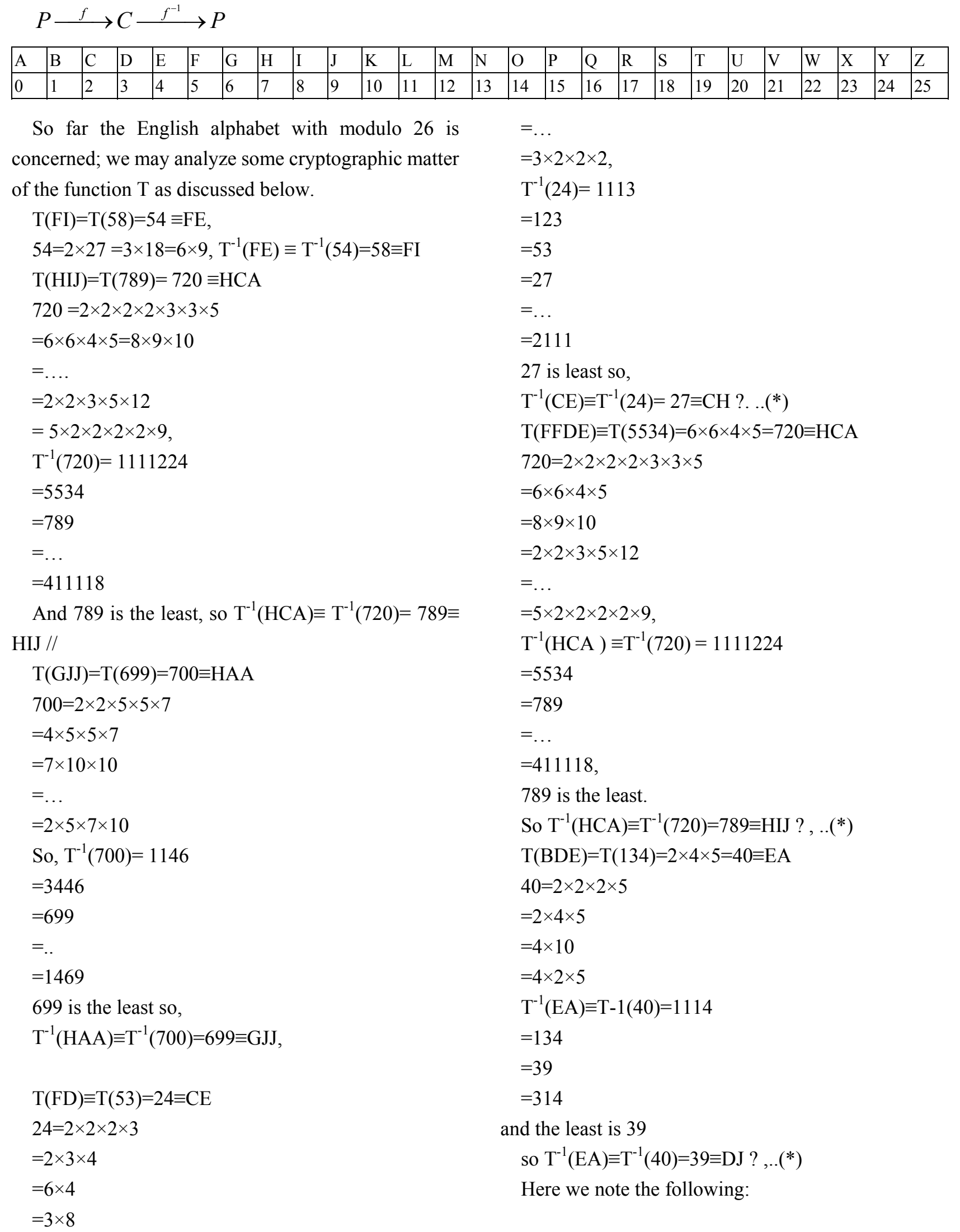




$$
\begin{aligned}
& F I \rightarrow 58 \stackrel{T}{\longrightarrow} 54 \rightarrow(G I \rightarrow 54) \stackrel{T^{-1}}{\longrightarrow} F I\left[\text { as } \mathrm{T}(58)=54, \mathrm{~T}^{-1}(54)=58\right] \\
& H I J \rightarrow 789 \stackrel{T}{\longrightarrow} 720 \rightarrow(H C A \rightarrow 720) \stackrel{T^{-1}}{\longrightarrow} H I J\left[\text { as } \mathrm{T}(789)=720, \mathrm{~T}^{-1}(720)=789\right] \\
& G J J \rightarrow 699 \stackrel{T}{\longrightarrow} 700 \rightarrow(H A A \rightarrow 700) \stackrel{T^{-1}}{\longrightarrow} \text { GJ }\left[\text { as } \mathrm{T}(699)=700, \mathrm{~T}^{-1}(700)=699\right]
\end{aligned}
$$

One may think about the above mentioned type of cryptographic deliberation. An arithmetic function $T$ discussed above with its inverse possibility as mentioned definitely leads one to a fertile involvement in the field of cryptography.

For another question that may one ask for is: For what positive integer $\mathrm{X}$ does $\mathrm{T}^{-1}(\mathrm{X})$ not exist? Clearly, $T^{-1}(1)$ does not exist. For $X>1, T^{-1}(X)$ will exist so long as $\mathrm{X}$ can be expressed as a product of factors, none of which is greater than 10 . If $X$ has any prime factor greater than 7 , this factorization cannot be done. Thus the answer to the question is 1 , and any positive integer having a prime divisor greater than 7.

Again we note that in above with $(*)$ marks the cases are not so. And it would be an algorithmic exercise to be dealt with by a cryptographer. One may hope for so many algorithms to solve such a problem.

\subsection{Some Restricted Views}

We present four restricted cases of $\mathrm{T}$ making an upper bound of the number $\mathrm{N}$ in consideration as follows.

We first take the case $\mathrm{N}<300$ with $\mathrm{T}(\mathrm{N})=\mathrm{N}+1$, it obviously works for one digit numbers vz., $1,2,3,4,5,6,7,8,9$. Now we consider the case of two digit numbers and if $\mathrm{N}=10 \mathrm{~A}+\mathrm{B}$, we have $(\mathrm{A}+1)(\mathrm{B}+1)$ $=10 \mathrm{~A}+\mathrm{B}+1$ and this gives us $\mathrm{A}(\mathrm{B}+1)=10 \mathrm{~A}$ leading to $\mathrm{B}=9$. Thus the related two digit numbers would be $19,29,39,49,59,69,79,89,99$.

Finally comes the turn of three digit numbers. If $\mathrm{N}=100 \mathrm{~A}+10 \mathrm{~B}+\mathrm{C}$, the possible values of $\mathrm{A}$ are 1 and 2 only. $\mathrm{A}$ brief analysis for $\mathrm{A}=1$ and for $\mathrm{A}=2$ lead to the values: 199,299 .
Next we consider the case $\mathrm{N}<100$ with $\mathrm{T}(\mathrm{N})=\mathrm{N}$,

This cannot work for a one digit number. Now for a two digit number $\mathrm{N}=10 \mathrm{~A}+\mathrm{B} \quad \mathrm{T}$ $(\mathrm{N})=\mathrm{N} \Rightarrow(\mathrm{A}+1)(\mathrm{B}+1)=10 \mathrm{~A}+\mathrm{B} \Rightarrow \mathrm{AB}+\mathrm{A}+\mathrm{B}+1=10 \mathrm{~A}+\mathrm{B}$ $\Rightarrow 1=\mathrm{A}(9-\mathrm{B}) \Rightarrow \mathrm{A}=1, \mathrm{~B}=8$, hence $\mathrm{N}=18 . / /$

The third case is $\mathrm{N}<100$ such that $\mathrm{T}(\mathrm{N})=\mathrm{N}-20$.

If $\mathrm{N}=10 \mathrm{~A}+\mathrm{B}$, then $(\mathrm{A}+1)(\mathrm{B}+1)=10 \mathrm{~A}+\mathrm{B}-20$ leads to AB-9A $=-21$

$9 A-A B=21 \Rightarrow A(9-B)=21 \Rightarrow A \mid 21 \Rightarrow A=1,3,7$. For $\mathrm{A}=1,9-\mathrm{B}=21$, (no solution), $\mathrm{A}=3,9-\mathrm{B}=7 \Rightarrow \mathrm{B}=2, \mathrm{~A}=7$, $9-\mathrm{B}=3 \Rightarrow \mathrm{B}=6$. Hence the required numbers are $32,76 . / /$

The fourth case we consider is $\mathrm{N}<100$ such that $\mathrm{T}$ $(\mathrm{N})=7 \mathrm{~N} / 8$

For a one digit number, we get $\mathrm{N}+1=7 \mathrm{~N} / 8$, which leads to an impossibility . If $\mathrm{N}=10 \mathrm{~A}+\mathrm{B}, \mathrm{T}$ $(\mathrm{N})=7 \mathrm{~N} / 8 \Rightarrow(\mathrm{A}+1)(\mathrm{B}+1)=7(10 \mathrm{~A}+\mathrm{B}) / 8$ $8(\mathrm{~A}+1)(\mathrm{B}+1)=7(10 \mathrm{~A}+\mathrm{B}) \Rightarrow 7|8(\mathrm{~A}+1)(\mathrm{B}+1) \Rightarrow 7|(\mathrm{A}+1)$ or $(\mathrm{B}+1) \Rightarrow \mathrm{A}=6$ or $\mathrm{B}=6$ and $\mathrm{A}=6 \Rightarrow 7 \mathrm{~B}=52$, (no solution). $B=6 \Rightarrow 2=2 A \Rightarrow A=1$; thus the only number is $16 . / /$

Thus,

Note:

2.6(i) if $\mathrm{N}<300$ such that $\mathrm{T}(\mathrm{N})=\mathrm{N}+1$, then the solutions are

$1,2,3,4,5,6,7,8,9,19,29,39,49,59,69,79,89,99,199,29$ 9

2.6(ii) if $\mathrm{N}<100$ with $\mathrm{T}(\mathrm{N})=\mathrm{N}$, then the only solution is 18

2.6 (iii) if $\mathrm{N}<100$ such that $\mathrm{T}(\mathrm{N})=\mathrm{N}-20$, the required numbers are 32,76

2.6 (iv) if $\mathrm{N}<100$ such that $\mathrm{T}(\mathrm{N})=7 \mathrm{~N} / 8$, the only number is 16 . 


\section{Main Results}

\subsection{Some restricted formulation}

The following are some interesting restricted formulation of $\mathrm{T}$.

3.1.1_: $T(10 A+B)=[T(A)][B+1]$, where $A$ and $B$ are integer with $\mathrm{A} \geq 1$ and

$0 \leq \mathrm{B} \leq 9$.

Proof :

If $\mathrm{A}=\sum_{i=0}^{n} a_{i} \cdot 10^{i}$, then $\mathrm{T}(\mathrm{A})=\prod_{i=0}^{n}\left(a_{i}+1\right) ; 10 \mathrm{~A}+\mathrm{B}$ $=\left[\sum_{i=0}^{n+1} \alpha_{i} \cdot 10^{i}, \alpha_{0}=0, \alpha_{1}=a_{0}, . . \alpha_{n+1}=a_{n}\right]+\mathrm{B}$, so $\mathrm{T}(10 \mathrm{~A}+\mathrm{B})=\left[\prod_{i=0}^{n+1}\left(\alpha_{i}+1\right)\right][\mathrm{B}+1]=\left[\prod_{i=0}^{n}\left(a_{i}+1\right)\right][\mathrm{B}+1$ ]$=[\mathrm{T}(\mathrm{A})][\mathrm{B}+1] . / /$

Result 3.1.2 $\mathrm{T}(\mathrm{N}) \leq \mathrm{N}+1$ for all positive integer $\mathrm{N}$.

Proof:

The proof would by induction on the number of digits $f$ the number.

The result is true for all single digit numbers.

Assume it holds for all $\mathrm{k}$ digit numbers $(\mathrm{k} \geq 1)$. Let $\mathrm{N}$ have $\mathrm{k}+1$ digits. Then if $\mathrm{N}=10 \mathrm{~A}+\mathrm{B}$, [where $\mathrm{A}$ has $\mathrm{k}$-digits and $0 \leq \mathrm{B} \leq 9]$. Now by what we have proved above, $\quad \mathrm{T}(\mathrm{N})=[\mathrm{T}(\mathrm{A})][\mathrm{B}+1] \leq[\mathrm{A}+1][\mathrm{B}+1] \quad$ (induction hypothesis)

$\mathrm{AB}+\mathrm{A}+\mathrm{B}+1=[\mathrm{B}+1] \mathrm{A}+\mathrm{B}+1 \leq 10 \mathrm{~A}+\mathrm{B}+1=\mathrm{N}+1$.

By induction, therefore, the statements hold for all N.//

Result 3.1.3 : For all positive integers $N, T(N)=N$ has only solution(s) found in our above discussion, i.e., 18

Proof:

Let $\mathrm{N}=10 \mathrm{~A}+\mathrm{B}$, where $\mathrm{A}>0$ and $0 \leq \mathrm{B} \leq 9$ [note that for $\mathrm{A}=0, \mathrm{~T}(\mathrm{~B})=\mathrm{B}+1$, not $\mathrm{B}]$, and by above, 1(i), $\mathrm{T}(10 \mathrm{~A}+\mathrm{B}]=[\mathrm{T}(\mathrm{A})][\mathrm{B}+1]$ gives, $[\mathrm{T}(\mathrm{A})][\mathrm{B}+1]=10 \mathrm{~A}+\mathrm{B}$, so $(\mathrm{B}+1)|(10 \mathrm{~A}+\mathrm{B}) \Rightarrow(\mathrm{B}+1)|(10 \mathrm{~A}+\mathrm{B}+1-1)$

$\Rightarrow(\mathrm{B}+1)|(10 \mathrm{~A}-1)+(\mathrm{B}+1) \Rightarrow(\mathrm{B}+1)|(10 \mathrm{~A}+1)$, so $\mathrm{B}$ is even.

But $10 \mathrm{~A}+\mathrm{B}=[\mathrm{T}(\mathrm{A})][\mathrm{B}+1] \leq[\mathrm{A}+1][\mathrm{B}+1][$ by $1(\mathrm{ii})]$ $=\mathrm{AB}+\mathrm{A}+\mathrm{B}+1$

$\Rightarrow 9 \mathrm{~A} \leq \mathrm{AB}+1, \quad$ so $\quad \mathrm{A}(9-\mathrm{B}) \leq 1 \Rightarrow \mathrm{B}=9$. [Impossible, since $\mathrm{B}$ is even] or $\mathrm{A}=1, \mathrm{~B}=8$. Thus 18 is the only answer.//

Result 3.1.4 For all positive integers $\mathrm{N}, \mathrm{T}(\mathrm{N})=\mathrm{N}-20$ has only the solution(s) found in our

above discussion.

Proof: Since $T(N)>0, N \geq 21$. Let $N=10 A+B$, where $\mathrm{A} \geq 2$ and $0 \leq \mathrm{B} \leq 9$. Then $\mathrm{T}(10 \mathrm{~A}+\mathrm{B})=[\mathrm{T}(\mathrm{A})][\mathrm{B}+1][\mathrm{by}$ $1(\mathrm{ii})]=10 \mathrm{~A}+\mathrm{B}-20 \Rightarrow(\mathrm{B}+1) \mid(10 \mathrm{~A}+\mathrm{B}-20)$

$$
\Rightarrow(\mathrm{B}+1)
$$

$[10 \mathrm{~A}+(\mathrm{B}+1)-21] \Rightarrow(\mathrm{B}+1)|(10 \mathrm{~A}-21) \Rightarrow(\mathrm{B}+1)|[10(\mathrm{~A}-22)$ -1 ], so $B+1$ is odd, making $B$ even and $\leq 9$. Therefore $\mathrm{B}=0,2,4,6,8$.

$$
\text { Also }[\mathrm{T}(\mathrm{A})][\mathrm{B}+1] \leq[\mathrm{A}+1][\mathrm{B}+1] \text {, }
$$

so $10 \mathrm{~A}+\mathrm{B}-20 \leq(\mathrm{A}+1)(\mathrm{B}+1)=\mathrm{AB}+\mathrm{A}+\mathrm{B}+1 \Rightarrow \mathrm{A} \leq \frac{21}{9-B}$

Let us now consider the cases:

If $\mathrm{B}=0, \mathrm{~A} \leq 21 / 9 \Rightarrow \mathrm{A}=2$ and $\mathrm{N}=20$ (impossible, since $\mathrm{N} \geq 21$ ] No solution for $\mathrm{B}=0$.

If $B=2, A \leq 21 / 7=3 \Rightarrow A=2$ or $3, T(32)=32-20$, but $T$ $(22) \neq 22-20$. Hence, only solution is $N=32$.

If $\mathrm{B}=4,(\mathrm{~B}+1)|[10(\mathrm{~A}-2)-1] \Rightarrow 5|[10(\mathrm{~A}-2)-1]$, which is not possible, since $5 \mathrm{X}-1$.

If

$$
\mathrm{B}=6 \text {, }
$$

$(\mathrm{B}+1)|[10(\mathrm{~A}-2)-2] \Rightarrow 7|[10(\mathrm{~A}-2)-1] \Rightarrow 7|3 \mathrm{~A} \Rightarrow 7| \mathrm{A}$; then $\mathrm{A} \leq 21 / 3 \Rightarrow \mathrm{A}=7$. $\mathrm{T}(76)=76-20$. Hence another solution is $\mathrm{N}=76$.

If $B=8,(B+1)|[10(A-2)-1] \Rightarrow 9|[10(A-2)-1] \Rightarrow 9 \mid(A-3)$; then $\mathrm{A} \leq 21 \Rightarrow \mathrm{A}=3,12,21$.

$\mathrm{T}(38) \neq 38-20 ; \mathrm{T}(128)=128-20 ; \mathrm{T}(218) \neq 218-20$.

Thus the only solution is 32 and 76.//

Result 3.1.5: $\quad \mathrm{T} \quad(0)+\mathrm{T}(1)+\mathrm{T}(2)+\mathrm{T}(3)+\ldots$ $+\mathrm{T}\left(10^{\mathrm{k}}-1\right)=55^{\mathrm{k}}$,for all positive integer $\mathrm{k}$ with

$\mathrm{T}(0)=1$

Proof: The proof is by induction. Let us first illustrate this for $\mathrm{k}=1,2,3$. For $\mathrm{k}=1, \mathrm{~T}(0)+\mathrm{T}(1)+\ldots .+\mathrm{T}$ $(9)=1+2+\ldots+10=55^{1}$

For $\mathrm{k}=2$,

$\mathrm{T}(0)+\mathrm{T}(1)+\ldots+\mathrm{T}(99)$

$=[\mathrm{T}(0)+\mathrm{T}(10)+\mathrm{T}(20)+\ldots .+\mathrm{T}(99)]+[\mathrm{T}(1)+\mathrm{T}(11)+\mathrm{T}(2$ $1)+\ldots+\mathrm{T}(91)+\ldots+$

$[\mathrm{T}(9)+\mathrm{T}(19)+\mathrm{T}(29)+\ldots .+\mathrm{T}(99)[\mathrm{using}$ 


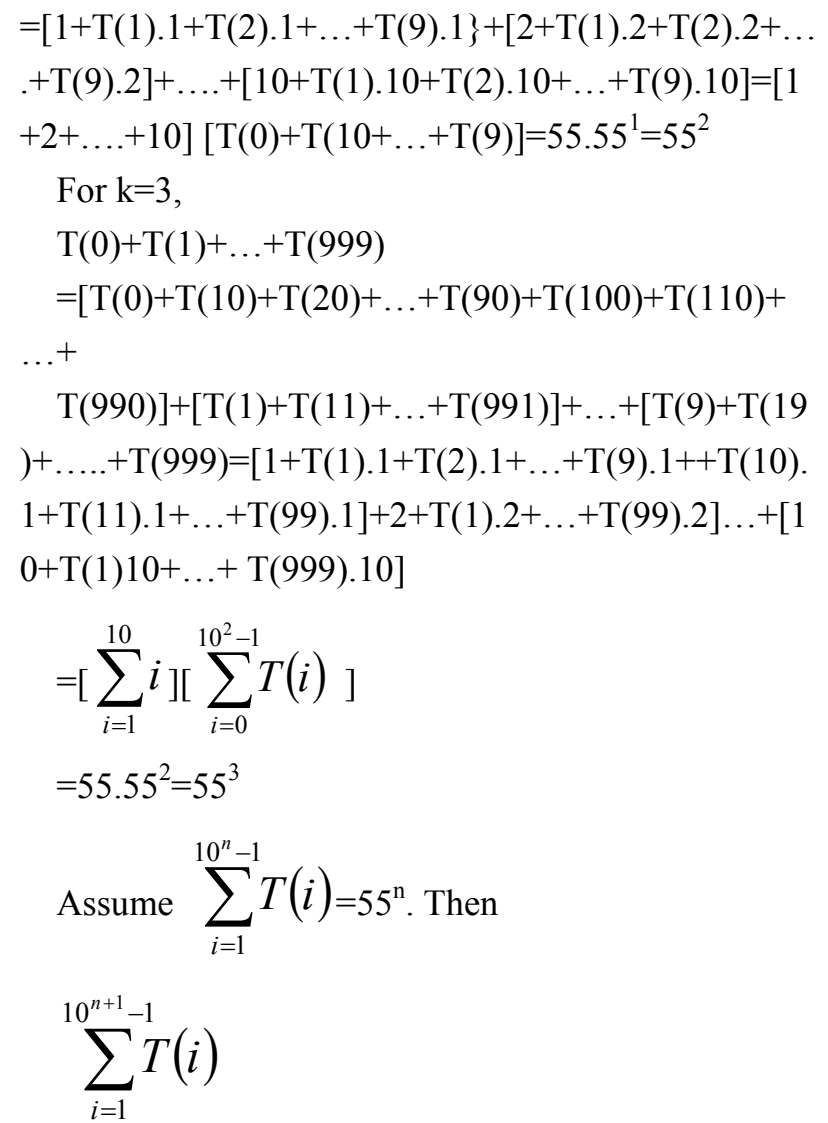

3.2(ii) If $\mathrm{p}=3$, then $\mathrm{T}(\mathrm{N})$ is the number of terms in
$=\left[1+\mathrm{T}(1) \cdot 1+\mathrm{T}(2) \cdot 1+\ldots .+\mathrm{T}\left(10^{\mathrm{n}}-1\right) \cdot 1\right]+[2+\mathrm{T}(1) \cdot 2+\ldots$

$+\mathrm{T}(10 \mathrm{n}-1) .2]+\ldots+[10+\mathrm{T}(1) 10+\ldots+\mathrm{T}(10 \mathrm{n}-1) .10]$

$$
=\left[\sum_{i=1}^{10} i\right]\left[\sum_{i=1}^{10^{n}-1} T(i)\right]
$$

$=55.55^{\mathrm{n}}=55^{\mathrm{n}+1}$; thus satisfying the induction hypothesis.

[Note: It can be shown that $\left[\mathrm{T}(0)^{2}+\mathrm{T}(1)^{2}+\ldots+\left[\mathrm{T}\left(10^{\mathrm{k}}-1\right)\right]^{2}=385^{\mathrm{k}}\right.$, and in general

$$
\left[\sum_{i=1}^{10^{k}-1} T(i)\right]^{R}=\sum_{i=0}^{9}\left([T(i)]^{R}\right)^{k} .
$$

\subsection{T function and Pascal Triangle}

Thus the function $\mathrm{T}$ has many fascinating properties, including the fact that when $\mathrm{N}$ is written in base $\mathrm{p}$ (a prime) and $\mathrm{T}(\mathrm{N})$ is suitably defined, then $\mathrm{T}(\mathrm{N})$ is the number of terms in the $\mathrm{N}^{\text {th }}$ row of Pascal's triangle which are not divisible by $\mathrm{p}$.

$3 \quad 1$

6

10

4

1

20

15

$\begin{array}{ll}6 & 1\end{array}$

$\begin{array}{llll}35 & 21 & 7 & 1\end{array}$

70

56

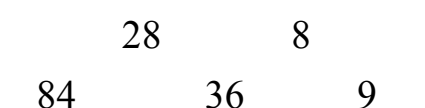

$\begin{array}{llllll}126 & 84 & 36 & 9 & 1\end{array}$

$\begin{array}{llllll}252 & 210 & 120 & 45 & 10 & 1\end{array}$

the $\mathrm{N}+1^{\text {th }}$ row of Pascal's triangle which are not divisible by 3 .

Verification: $\quad \mathrm{T}(1)=2, \quad \mathrm{~T}(10)=2=2$,

$\mathrm{T}(11)=2.2=4, \mathrm{~T}(12)=2.3=6, \mathrm{~T}(20)=3$,

$\mathrm{T}(101)=2.2=4$,

3.2(iii) If $\mathrm{p}=5$, then $\mathrm{T}(\mathrm{N})$ is the number of terms in the $\mathrm{N}+1^{\text {th }}$ row of Pascal's triangle which are not divisible by 5 . 
Verification: $\quad \mathrm{T}(1)=2, \quad \mathrm{~T}(10)=2, \quad 11$

$\mathrm{T}(11)=2.2=4, \mathrm{~T}(12)=2.3=6, \mathrm{~T}(20)=3$,

3.2(iv) If $p=7$, then $T(N)$ is the number of terms in the $\mathrm{N}+1^{\text {th }}$ row of Pascal's triangle which are not divisible by 7 .

Verification: $\quad \mathrm{T}(1)=2, \quad \mathrm{~T}(10)=2$,

$\mathrm{T}(11)=2.2=4, \mathrm{~T}(12)=2.3=6$. etc

$\mathrm{T}(123)=2 \cdot 3 \cdot 4=\mathrm{T}(1) \cdot \mathrm{T}(2) \cdot \mathrm{T}(3), \quad \mathrm{T}(4)=\mathrm{T}\left(2^{2}\right)=5$, $\mathrm{T}(25)=\mathrm{T}\left(5^{2}\right)=3.6=18$

Note: We note that the function $\mathrm{T}$ is digital multiplicative in the sense :

$$
T(\underline{a b})=(a+1)(b+1)=T(a) T(b) \text {,i.e.T }(34)=(3
$$

$+1)(4+1)=\mathrm{T}(3) \mathrm{T}(4)$.

\subsection{Digital Additive Property of T}

Now we investigate some interesting properties such as the corresponding so called digital additive property in some details leading to some interesting characteristics of $\mathrm{T}$.

The following types of examples direct us for such an investigation.

We first note here the following

$2.2=1(2+2), \quad 3.6=2(3+6), 4.4=2(4+4), \quad 6.3=2(6+3)$, $6.6=3(6+6), 8.8=4(8+8), 10.10=5(10+10)$ etc.

We are interested to find for which $\mathrm{n} \in \mathrm{N}$ such that $T(\underline{m n})=k[T(m)+T(n)]=$ ? (two digit numbers) [ $0<m \leq 9,0 \leq n \leq 9$ ]

$\mathrm{LHS}=(\mathrm{m}+1)(\mathrm{n}+1)$ and $\mathrm{RHS}=\mathrm{k}[(\mathrm{m}+1)+(\mathrm{n}+1)]$

So if $\mathrm{LHS}=\mathrm{RHS}$ then

$\mathrm{mn}+\mathrm{m}+\mathrm{n}+1=\mathrm{k}[\mathrm{m}+\mathrm{n}+2] \Rightarrow \mathrm{mn}=\mathrm{m}(\mathrm{k}-1)+\mathrm{n}(\mathrm{k}-1)+(2 \mathrm{k}-1)$

(*)

now we take

$\mathrm{k}=1$, the $(*)$ gives, $\mathrm{mn}=1$ and therefore, $\mathrm{m}=\mathrm{n}=1 \therefore$ the number is 11

$\mathrm{m}>1$, gives no solution as $\mathrm{mn}=1$.

Result $\quad 3.3 .1 \quad$ The equation

$T(\underline{m n})=[T(m)+T(n)]$ has only one solution viz.,

For $\mathrm{k}=2,(*)$ gives $\mathrm{mn}=\mathrm{m}+\mathrm{n}+3$, then

$\mathrm{m}=1 \Rightarrow \mathrm{n}=1+\mathrm{n}+3=\mathrm{n}+4$, not possible.

$\mathrm{m}=2 \Rightarrow 2 \mathrm{n}=2+\mathrm{n}+3 \Rightarrow \mathrm{n}=5 \therefore$ the number is 25

$\mathrm{m}=3 \Rightarrow 3 \mathrm{n}=3+\mathrm{n}+3 \Rightarrow 2 \mathrm{n}=6 \Rightarrow \mathrm{n}=3 \therefore$ the number is 33

$m=4 \Rightarrow 4 n=4+n+3 \Rightarrow 3 n=7$, not possible

$m=5 \Rightarrow 5 n=5+n+3 \Rightarrow 4 n=8 \Rightarrow n=2, \therefore$ the number is 52

$\mathrm{m}=6,7,8,9 \Rightarrow 5 \mathrm{n}=9,6 \mathrm{n}=10,7 \mathrm{n}=11,8 \mathrm{n}=12$ and none of these possible.

Result $\quad 3.3 .2 \quad$ The equation $T(\underline{m n})=2[T(m)+T(n)] 25,33$ andd 52 as its solution.

Now we take $\mathrm{k}=3$, then $(*)$ gives $\mathrm{mn}=2 \mathrm{~m}+2 \mathrm{n}+5$

then $\mathrm{m}=1 \Rightarrow \mathrm{n}=2+2 \mathrm{n}+5$, not possible

$\mathrm{m}=2 \Rightarrow 2 \mathrm{n}=4+2 \mathrm{n}+5$, not possible

$\mathrm{m}=3 \Rightarrow 3 \mathrm{n}=6+2 \mathrm{n}+5 \Rightarrow \mathrm{n}=11$, not possible

$\mathrm{m}=4 \Rightarrow 4 \mathrm{n}=8+2 \mathrm{n}+5 \Rightarrow 2 \mathrm{n}=13$, not possible

$\mathrm{m}=5 \Rightarrow 5 \mathrm{n}=10+2 \mathrm{n}+5 \Rightarrow 3 \mathrm{n}=15 \Rightarrow \mathrm{n}=5 \therefore$ the number is 55

$m=6,7,8,9$ gives $4 n=17,5 n=19,6 n=21,7 n=23$ and none of these possible.

Result $\quad 3.3 .3 \quad$ The equation $T(\underline{m n})=3[T(m)+T(n)]$ has 55 as its only solution.

We now take the case of $\mathrm{k}=4$. Then $(*)$ gives $m n=3 m+3 n+7$

Then $\mathrm{m}=1 \Rightarrow \mathrm{n}=3+3 \mathrm{n}+7 \Rightarrow 0=2 \mathrm{n}+10$, not possible similarly,

$$
\mathrm{m}=2,3,4,5,6,7,8,9 \quad \text { give }
$$

=-ve, $16=0, n=19, n=11,3 n=25$,

$\mathrm{m}=7 \Rightarrow 4 \mathrm{n}=28 \Rightarrow \mathrm{n}=7 \therefore$ the number is 77

$m=8,9$ give $n=5 n=31,6 n=34$ not possible.

Result 3.3.4 The equation $T(\underline{m n})=4[T(m)+T(n)]$ has 77 as its only solution.

Next we consider $\mathrm{k}=5$. Here, $(*)$ gives $m n=4 m+4 n+9$, 
Then $\mathrm{m}=1,2,3,5,6,7,8 \Rightarrow \mathrm{n}$ is -ve,-ve,-ve, fraction, fraction, fraction.

$$
\begin{aligned}
& \text { And } n=4 \text { gives } 0=21 \\
& m=9 \Rightarrow 9 n=36+4 n+9 \Rightarrow 5 n=45 \Rightarrow n=9 \text {, the number is }
\end{aligned}
$$
99.

Result $\quad 3.3 .5 \quad$ The equation

$T(\underline{m n})=5[T(m)+T(n)]$ has 99 as its only solution.

Now propose for the following

\section{Proposition 3.3.6}

$T(\underline{m n})=k[T(m)+T(n)]$ has no solution for $\mathrm{k}>5$.

\section{Proof:}

Here, $\mathrm{k}>5$, then $\mathrm{mn}=\mathrm{m}(\mathrm{k}-1)+\mathrm{n}(\mathrm{k}-1)+(2 \mathrm{k}-1)$ gives

$m n>4 m+4 n+9$, or $m n-9>4 m+4 n$,

$-9>4 m-m n+4 n=m(4-n)+4 n$

$-9>\mathrm{m}(4-\mathrm{n})+4 \mathrm{n}, \mathrm{m}=1,2,3,4$ no, 5

Now, $\mathrm{m}=1,2,3 \Rightarrow \mathrm{n}<0, \mathrm{~m}=4 \Rightarrow 25<0, \mathrm{~m}=5,6,7,8,9 \Rightarrow$ $\mathrm{n}>9$.

Thus for $\mathrm{k}>5$ the chosen equation has no solution.

\section{Conclusion}

As already mentioned that this paper is on a rarely used arithmetic function that seems to contains much potential so far many aspects of number theory is concerned such, binomial distribution, cryptographic information with possible admissible properly suited inverse, on the structure of the naturals depending upon the its digital presentation with various bases .

\section{Acknowledgment}

We acknowledge Maitrayee Chowdhury for her help rendered in proof reading of the manuscript.

Acknowledgement is due to UGC (New Delhi) as the paper is prepared under emeritus fellowship scheme of the author.

\section{References}

[1] N Koblitz : A Course in number theory and cryptography, second edition, Springer verlag, 1997,

[2] Ramesh :Some properties and applications of a new arithmetic function Kumarmuthamulai in analytic number theory -NNTDM 17(2011),3,38-48

[3] Niven,I, Zuckerman,H.S. : An introduction to theory of numbers, Theory of numbers-Montgomery,H.L. John Wiley (New York), 1991 